\title{
Suppression of Highly Pathogenic Avian Influenza A/H5N1 Infection Using Migratory Antibody Passed from Mother to Chick
}

\section{Kazuhide Adachi' ${ }^{1}$, Ganita Kurniasih Suryaman², Retno Damajanti Soejoedono², Ekowati Handharyani' ${ }^{2}$, Yasuhiro Tsukamoto ${ }^{1 *}$}

\author{
${ }^{1}$ Department of Animal Hygiene, Graduate School of Environmental \& Biological Sciences, Kyoto Prefecture University, Kyoto, \\ Japan \\ ${ }^{2}$ Faculty of Veterinary Medicine, Bogor Agriculture University, Bogor, Indonesia \\ Email: *ytsuka@kpu.ac.jp
}

How to cite this paper: Adachi, K., Suryaman, G.K., Soejoedono, R.D., Handharyani, E. and Tsukamoto, Y. (2018) Suppression of Highly Pathogenic Avian Influenza A/H5N1 Infection Using Migratory Antibody Passed from Mother to Chick. World Journal of Vaccines, 8, 89-97. https://doi.org/10.4236/wjv.2018.84008

Received: November 17, 2018 Accepted: November 26, 2018 Published: November 29, 2018

Copyright $\odot 2018$ by authors and Scientific Research Publishing Inc. This work is licensed under the Creative Commons Attribution International License (CC BY 4.0).

http://creativecommons.org/licenses/by/4.0/

\begin{abstract}
Avian influenza is the most contagious disease not only in poultry, but also in humans. Avian influenza in humans occurs mainly in Southeast Asia, but no human-to-human pandemic has occurred. Meanwhile, outbreaks of avian influenza in poultry occur on a global scale and cause a large economic loss. Migration antibodies passed from mother birds via eggs are said to be an important component of the immune system that protects birds from infection. Thus, the immunity status of mother birds can determine the ability of offspring to defend against infection. In this study, we investigated the presence of anti-avian influenza virus antibody in chickens hatched on a poultry farm in Indonesia and examined the involvement of migratory antibodies in protecting against virus infection by infectious experiments of highly pathogenic avian influenza in chickens. Blood was collected from randomly selected chicks, and antibodies against avian influenza virus were evaluated in all birds. Since these young birds had no history of vaccination, the antibodies were deemed to have been transferred from the mother birds. The enzyme-linked immunosorbent assay antibody titer in each bird varied. Infection of these birds with highly pathogenic avian influenza virus $\mathrm{A} / \mathrm{H} 5 \mathrm{~N} 1$ intra-nasally resulted in a high mortality rate in chicks with low antibody titers but a low mortality rate in chicks with high antibody titers. These findings indicate that migratory antibody prevented highly pathogenic avian influenza $\mathrm{A} / \mathrm{H} 5 \mathrm{~N} 1$ infection in chicks, suggesting that such a preventive effect could also be expected with outdoor natural infection.
\end{abstract}

\section{Keywords}

Avian Flu, Influenza Virus, H5N1, Antibody, Chicken 


\section{Introduction}

Mammals are equipped with an immune system in which antibodies from mothers transfer to children through the placenta and breast milk. These antibodies are called migratory antibodies and are responsible for protecting young children with an incomplete immune function against infection. In egg-laying animals, such as birds, migratory antibodies can be transferred from mothers to their eggs, thereby protecting their offspring. Even in domestic chickens, migratory antibodies from mothers are useful for defense against various infectious diseases, and the mother's immune status determines the susceptibility of chicks to infection [1] [2] [3] [4]. As an example, in infectious encephalomyelitis, which is one of picornavirus infections in domestic fowls, chicks can be prevented the viral infections by vaccinating their mother birds [5].

Highly pathogenic avian influenza is the most feared infectious disease in poultry, and in recent years, a number of infectious and death cases have been reported in humans as well, mainly in Southeast Asia [6] [7] [8] [9] [10]. In avian flu-free countries, vaccination is not conducted, and if infection occurs, all suspected infected chickens must be disposed [11] [12]. Since mother birds do not have immunity against avian influenza in these areas, chicks are not given a migratory antibody from their mother. In contrast, chickens are naturally infected daily by viruses in areas where avian influenza is resident, and, in some cases, vaccination prevents viral infection [11] [12]. Antibodies against avian influenza virus are produced by chickens in such areas, suggesting that migratory antibodies may also exist in chicks, obtained from their mothers via eggs. Therefore, chicks may already have immunity to this virus at the time of hatching.

In the present study, the presence of anti-avian influenza virus antibodies in the blood of infant chicks hatched at a poultry farm in Indonesia was assessed, and the protective effect of transferred antibody on highly pathogenic avian influenza A/H5N1 infection was verified by infection experiments.

\section{Materials \& Methods}

\subsection{Chickens}

Thirty newly-hatched chicks were collected from poultry farms selected at random in Indonesia. We confirmed that these birds had no history of vaccination with avian influenza vaccine. In addition, specific-pathogen-free (SPF) chicks were purchased and used for experiments as controls. They were reared under conditions of water and feed provided ad libitum in BSL-3 facility, and blood was sampled at 10 days of age. The serum titer of antibodies against $\mathrm{A} / \mathrm{H} 5 \mathrm{~N} 1$ antigens was measured by an enzyme-linked immunosorbent assay (ELISA).

\subsection{ELISA}

The antibody titer was measured by an ELISA according to our previous report [13]. A/H5N1 antigens $(0.2 \mu \mathrm{g})$ (Protein Science, USA) in phosphate-buffered 
saline (PBS) were coated onto each well of 96-well ELISA plates and stored overnight at $4^{\circ} \mathrm{C}$. Each of the subsequent incubation steps was preceded by sufficient washing the wells with $0.05 \%$ Tween 20 in PBS. The wells were blocked from nonspecific binding by the addition of a commercial blocking reagent (DS Pharma Biomedical, Japan) and incubated at $37^{\circ} \mathrm{C}$ for $2 \mathrm{~h}$. The serial dilutions of subject serum from each chick were added vertically to the wells and incubated at $37^{\circ} \mathrm{C}$ for $1 \mathrm{~h}$. The serum from SPF chicks was also used as a negative control. Next, HRP-conjugated rabbit IgG against chicken IgY Fc fraction (Nakarai Tesque, Japan) diluted in PBS (1:5000) was dispensed into each well. The plate was incubated for $1 \mathrm{~h}$ at $37^{\circ} \mathrm{C}$. Later, a substrate buffer containing TMB (Sumitomo Bakelite, Japan) was added to each well, and samples were incubated at $37^{\circ} \mathrm{C}$ for $15 \mathrm{~min}$. The reaction was terminated by the addition of a stopping reagent (1.25 $\mathrm{M}$ sulfuric acid). The absorbance was recorded at $450 \mathrm{~nm}$ using the ELISA plate reader. The ELISA titers were defined as the reciprocal of the highest dilution of subject serum that produced an ELISA signal twice as intense as that from equivalently diluted SPF chick serum.

\subsection{Infection of Chickens with the Highly Pathogenic Avian Influenza Virus A/H5N1}

At 10 days of age, seventy-two chicks from farm and ten SPF chicks were inoculated intranasally with a field-isolated strain of $\mathrm{A} / \mathrm{H} 5 \mathrm{~N} 1$ virus (A/LAWANG/FKH-IPB/H5N1) at a dose of $10^{5} \mathrm{TCID}_{50}$ per bird. This virus strain was isolated from a chicken spontaneously infected with H5N1 in a local poultry farm in the Bogor area of Indonesia. Five days after the viral inoculation, the lethality of infected birds was scored as the percentage of dead birds. The surviving chickens were sacrificed by administration of overdose pentobarbital sodium solution. The tracheae and lungs of subjects were removed and immersed in 10\% neutral buffered formalin for further histopathology and immunostaining studies. All of the animal experiments were performed in accordance with the guidelines for studies with laboratory animals of the Kyoto Prefectural University Experimental Animal Committee. After completion of the experiment, all samples were completely sterilized by autoclave.

\subsection{Histopathology}

The formalin fixed samples were dehydrated with serial concentrations of ethanol and embedded with xylene and paraffin using an automatic embedding processor. The sections were then cut using a microtome and attached to slide-glasses. The sections were dried and de-paraffinized inxylene and ethanol and then stained with hematoxylin and eosin. They were next serial-dehydrated with ethanol and immersed in xylene before finally being mounted with cover-glass using Canada balsam and examined under a light microscope.

\subsection{Detection of A/H5N1 Virus Antigens in Infected Chicks}

The chick organs fixed in buffered formalin were washed in PBS, cut into 5-mm 
cubes, and soaked in 30\% sucrose in PBS overnight. The pieces were mounted in a compound, frozen, and cut into $20-\mu \mathrm{m}$ sections with a cryostat. The frozen sections were attached to glass slides and air-dried at room temperature. After being washed in PBS, the samples were incubated with an FITC conjugated ostrich IgY against $\mathrm{A} / \mathrm{H} 5 \mathrm{~N} 1$ viruses $(1: 1000)$ at $4^{\circ} \mathrm{C}$ overnight [13] [14] [15]. Finally, they were mounted with glycerol following sufficient washing with PBS, and specific signals for viral antigens were examined under a fluorescent microscope.

\section{Results}

\subsection{Antibody Titer against A/H5N1 Antigens in the Serum of Chicks from an Indonesian Poultry Farm}

The immunoreactivity of subject sera against $\mathrm{A} / \mathrm{H} 5 \mathrm{~N} 1$ virus was estimated by ELISA. The titers for A/H5N1 varied among the chicks, as shown in Figure 1. The antibody titer in chicks' blood was 102,400 at the maximum and 1600 at the minimum, and there were individual differences. This suggested that the amount and activity of transitional antibody from the mother differed among individual chicks.

\subsection{Lethality of A/H5N1-Infected Chickens}

The experimental challenge in SPF chickens (10 days old) with A/H5N1 caused high lethality among the birds (100\%) within 5 days after infection, indicating that this viral strain isolated from poultry farm was a highly virulent type (Figure 2). Of note, all SPF birds showed only slight symptoms, including dehydration and depression, followed by sudden death. In contrast, a large individual

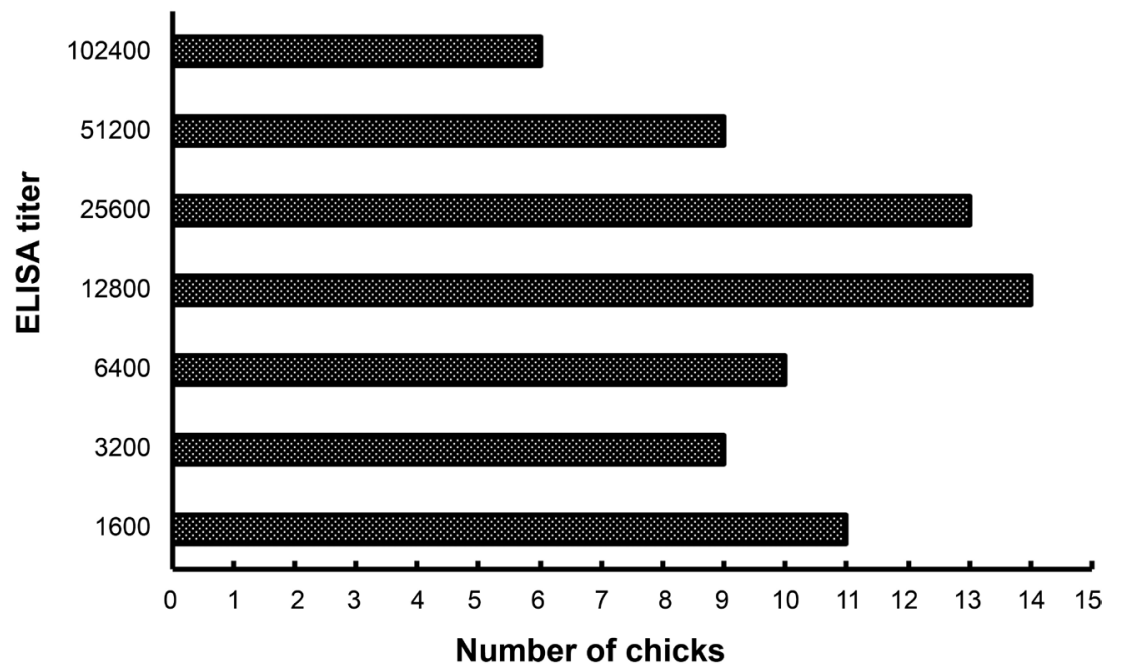

Figure 1. The transfer antibody titers in conventional chicks obtained from a poultry farm in Indonesia. The antibody titers against A/H5N1antigens in the sera from all chicks from the poultry farm were estimated by an enzyme-linked immunosorbent assay (ELISA). The ELISA titers were increased in all serum samples, with large individual variations among birds (range: 1600 - 102,400). 


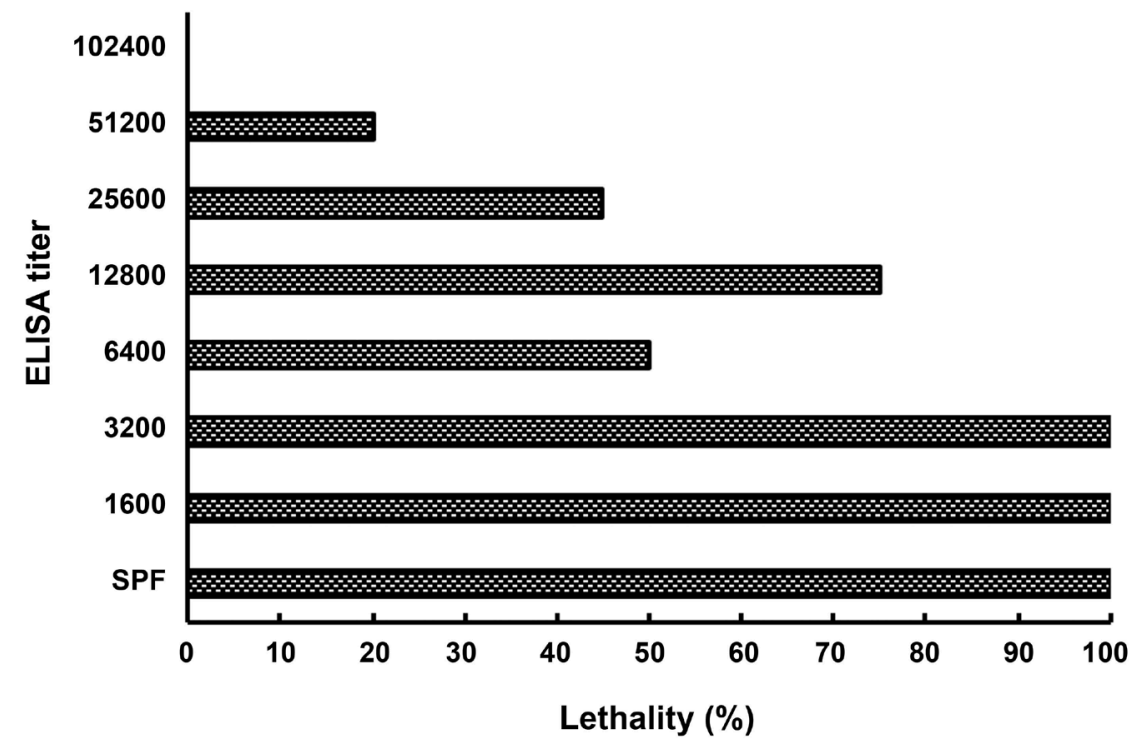

Figure 2. The transfer antibody titers of chicks and mortality rate due to highly pathogenic avian influenza $\mathrm{A} / \mathrm{H} 5 \mathrm{~N} 1$ infection. In chicks exhibiting low antibody titers, the mortality rate due to $\mathrm{A} / \mathrm{H} 5 \mathrm{~N} 1$ infection was high, while that in chicks with a high antibody titer was lower. When the antibody titer was 102,400 , death due to infection was completely suppressed.

difference was observed in the fatality rate of the infected chicks purchased from the poultry farm. The mortality rate due to virus infection was quite high in chicks with low antibody titers in blood, whereas the birds with high serum antibody titers showed low mortality. Furthermore, 100\% of birds with an ELISA value of 102,400 survived despite virus infection. We therefore concluded that viral infection could be suppressed in individuals with high transitional antibody titers.

\subsection{Histopathology}

The histopathological study of the infected SPF chickens showed the typical avian flu findings of acute inflammation accompanied by heterophilic infiltration, hemorrhaging, edema and severe congestion in various organs, mainly in the pulmonary tissues, including the trachea and lung (Figure 3). Pathological findings similar to SPF chickens were observed in dead chickens or infected chickens with low ELISA values $(\leq 25,600)$. The pulmonary sections of infected birds showed slight to moderate inflammation with epithelial necrosis and heterophilic infiltrations in the interstitium and parabronchial cavities. Severe hemorrhaging and congestion, accompanied by edema and mucosal exudates, were predominately seen. In contrast, the pathological reactions were decreased in the tracheae and lungs in survival chicks with an ELISA value exceeding 51,200. The edema, hemorrhaging, congestion and mucosal exudation were clearly inhibited in the lesions. Viral antigens were scarcely found in the trachea and pulmonary tissues. These findings were consistent with the results showing that the mortality of A/H5N1 chicks was decreased by higher titer of migratory antibodies. 


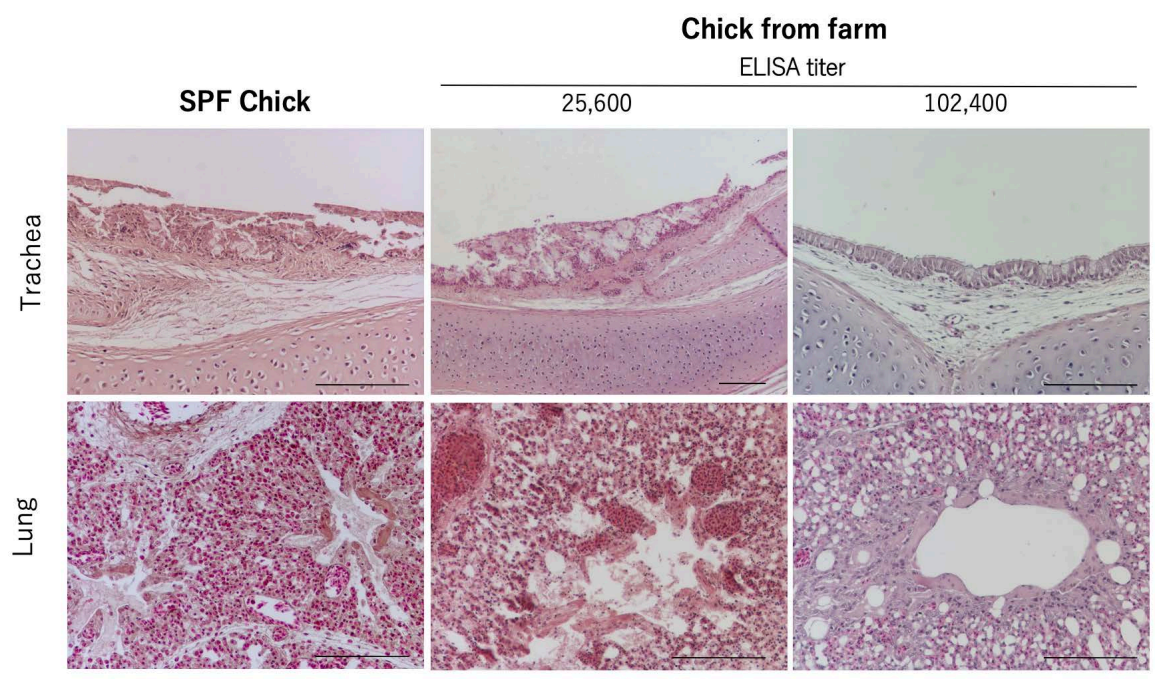

Figure 3. Histopathological findings of the trachea and lungs of highly pathogenic avian influenza virus A/H5N1-infected chicks. Paraffin sections were prepared, stained with $\mathrm{H}-\mathrm{E}$, and observed under a microscope. In chickens with an antibody titer of 25,600, acute inflammatory lesions, such as swelling, epithelial necrosis, interstitial edema and inflammatory cell infiltration, were observed in the trachea. In the lungs, severe congestion and necrotic cell debris, exudate and inflammatory cell infiltration were found in the para-bronchial lumen and interstitium. In contrast, histopathological findings were scarcely found in either the trachea or lung of chicks with an antibody titer of 102,400. Bars, 200 $\mu \mathrm{m}$.

\subsection{Detection of Viral Antigens in Trachea and Lung of Infected Chicks}

Viral antigens were found in the tracheal epithelial cells and pulmonary tissues of dead chickens or infected chickens with low ELISA values $(\leq 25,600)$. In contrast, viral antigens were scarcely seen in the pulmonary tissues of in surviving chicks showing ELISA values exceeding 51,200 (Figure 4).

\section{Discussion}

The present study confirmed that antibodies against avian influenza virus A/H5N1 existed in chicks from a poultry farm in Indonesia. Since these birds had no history of vaccination, we concluded that they had migratory antibodies obtained from their mother. However, since the mother's vaccination history was unknown, we could not confirm whether the migratory antibody was the influence of vaccination of the mother bird or had been acquired by natural infection. Given that the antibody titer against the A/H5N1 virus varied greatly among the birds, we predicted that susceptibility to avian influenza infection would vary among animals at chicken farms in Indonesia.

The $\mathrm{A} / \mathrm{H} 5 \mathrm{~N} 1$ virus used for infection experiments on conventional chicks was a field isolate from Indonesia and proved to be highly pathogenic to chickens, as the infected SPF chicken shows a 100\% mortality rate. Regarding the conventional chicks obtained from farms, a high mortality rate was also observed in individuals with low antibody ELISA values. In contrast, the mortality rate drastically 


\section{ELISA titer of Chick Serum}

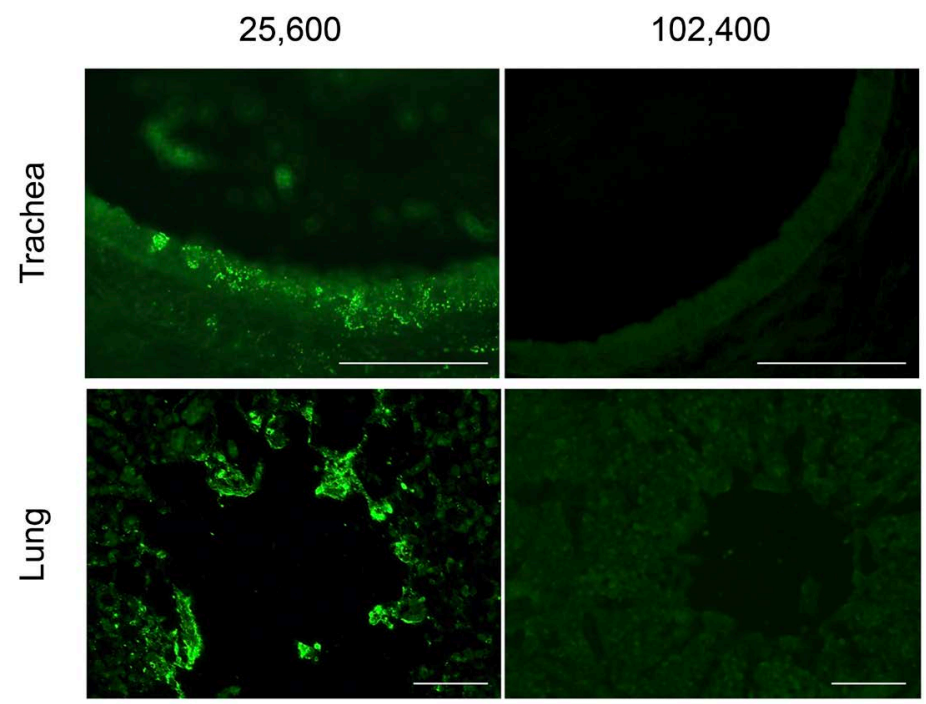

Figure 4. Viral antigen titers in the trachea and lungs of highly pathogenic avian influenza virus A/H5N1-infected chicks. Frozen sections of tracheae and lungs were cut, and indirect immunofluorescence staining was performed with anti-H5N1 antibody and FITC-conjugated secondary antibody. In chickens with an antibody titer of 25,600, viral antigens were detected in the tracheal and parabronchial epithelial cells in the lung. In contrast, specific signals of fluorescence were scarcely found in either the trachea or lung of chicks with an antibody titer of 102,400. Bars, $200 \mu \mathrm{m}$.

decreased in chicks with an antibody titer of $\geq 51,200$, and none with values exceeding 102,400 died. These findings indicate that the antibody transferred from the mother had neutralizing activities against $\mathrm{A} / \mathrm{H} 5 \mathrm{~N} 1$ virus infections and that the birds with an antibody titer above a certain level were resistant to death from avian influenza. At present, there are benefits and drawbacks for employing influenza vaccines in domestic fowls: 1 ) in avian influenza-free countries, it is difficult to diagnose natural infections; 2) the virus resides in the poultry body; and 3) the virus may mutate and become able to infect pigs or humans, causing a pandemic of a novel influenzas train [9] [11] [12].

Our findings here suggest that the transfer of antibodies from mother birds to their chicks may be a way to prevent avian influenza infection in the offspring. Maternal antibodies migration to chicks is considered effective for preventing virus infection, but the development of a good-quality vaccine and improvements in existing vaccination programs are required.

\section{Acknowledgements}

We thank Miss Akari Iki and Mrs. Hatsuki Matsunaga at Kyoto Prefecture University for their valuable technical support.

\section{Conflicts of Interest}

The authors declare that there are no conflicts of interest that could be perceived 
as prejudicing the impartiality of the research reported.

\section{References}

[1] Hamal, K.R., Burgess, S.C., Pevzner, I.Y. and Erf, G.F. (2006) Maternal Antibody Transfer from Dams to Their Egg Yolks, Egg Whites, and Chicks in Meat Lines of Chickens. Poultry Science, 85, 1364-1372. https://doi.org/10.1093/ps/85.8.1364

[2] Schade, R., Pfister, C., Halatsch, R. and Henklein, P. (1991) Polyclonal IgY Antibodies from Chicken Egg Yolk. An Alternative to the Production of Mammalian IgG Type Antibodies in Rabbits. ATLA, 19, 403-419.

[3] Schade, R., Schniering, A. and Hlinak, A. (1992) Polyclonal Avian Antibodies Extracted from Egg Yolk as an Alternative to the Production of Antibodies in Mammals: A Review. ALTEX, 9, 43-56.

[4] Zhang, X., Calvert, R.A., Sutton, B.J. and Doré, K.A. (2017) IgY: A Key Isotype in Antibody Evolution. Biological Reviews Cambridge Philosophical Society, 92, 2144-2156. https://doi.org/10.1111/brv.12325

[5] Calnek, B.W., Luginbuhl, R.E. and Helmboldt, C.F. (1997) Avian Encephalomyelitis. In: Calnek, B.W., Barnes, H.J., Beard, C.W., McDougald, L.R. and Saif, Y.M., Eds., Diseases of Poultry, 10th Edition, Iowa State University Press, Iowa, 571-582.

[6] Horman, W.S.J., Nguyen, T.H.O., Kedzierska, K., Bean, A.G.D. and Layton, D.S. (2018) The Drivers of Pathology in Zoonotic Avian Influenza: The Interplay Between Host and Pathogen. Frontiers in Immunology, 9, 1812.

[7] Chatziprodromidou, I.P., Arvanitidou, M., Guitian, J., Apostolou, T., Vantarakis, G. and Vantarakis (2018) Global Avian Influenza Outbreaks 2010-2016: A Systematic Review of Their Distribution, Avian Species and Virus Subtype. Systematic Reviews, 7, 17. https://doi.org/10.1186/s13643-018-0691-Z

[8] Suarez, D.L. and Schultz-Cherry, S. (2000) Immunology of Avian Influenza Virus: A Review. Developmental \& Comparative Immunology, 24, 269-283. https://doi.org/10.1016/S0145-305X(99)00078-6

[9] Alexander, D.J. and Brown, I.H. (2000) Recent Zoonoses Caused by Influenza A Viruses. Revue Scientifique et Technique, 19, 197-225. https://doi.org/10.20506/rst.19.1.1220

[10] Harfoot, R. and Webby, R.J. (2017) H5 influenza, A Global Update. Journal of Microbiology, 55, 196-203. https://doi.org/10.1007/s12275-017-7062-7

[11] Artois, J., Ippoliti, C., Conte, A., Dhingra, M.S., Alfonso, P., Tahawy, A.E., Elbestawy, A., Ellakany, H.F. and Gilbert, M. (2018) Avian Influenza A (H5N1) Outbreaks in Different Poultry Farm Types in Egypt: The Effect of Vaccination, Closing Status and Farm Size. BMC Veterinary Research, 14, 187. https://doi.org/10.1186/s12917-018-1519-8

[12] Swayne, D.E., Spackman, E. and Pantin-Jackwood, M. (2014) Success Factors for Avian Influenza Vaccine Use in Poultry and Potential Impact at the Wild Bird-Agricultural Interface. EcoHealth, 11, 94-108. https://doi.org/10.1007/s10393-013-0861-3

[13] Adachi, K., Takama, K., Ozaki, M., Fukuda, K., Endo, I., Yamamoto, R. and Tsukamoto, Y. (2008) Inhibition of H5N1 Avian Influenza Virus Infection by Ostrich Antibodies. Molecular Medicine Reports, 1, 2003-2009.

[14] Adachi, K., Kato, T., Kirimura, N., Kubota, Y., Shiba, H. and Tsukamoto, Y. (2014) Double Infections with Avian $\mathrm{A} / \mathrm{H} 5 \mathrm{~N} 1$ and Swine $\mathrm{A} / \mathrm{H} 1 \mathrm{~N} 1$ Influenza Viruses in Chickens. American International Journal of Biology, 2, 58-94. 
https://doi.org/10.15640/aijb.v2n3-4a6

[15] Kamiyama, Y., Adachi, K., Handharyani, E., Soejoedono, R.D., Kusano, T., Inai, M., Tsukamoto, M., Kashiwagi, S. and Tsukamoto, Y. (2011) Protection from Avian Influenza H5N1 Virus Infection with Antibody-Impregnated Filters. Virology Journal, 8, 54. (Online) https://doi.org/10.1186/1743-422X-8-54 